\title{
The major circulating immunosuppressive activity in American visceral leishmaniasis patients is associated with a high-molecular weight fraction and is not mediated by $\operatorname{IgG}, \operatorname{IgG}$ immune complexes or lipoproteins
}

\author{
N.M. Soares ${ }^{\text {a,b,*, }}$, T.P.L. Ferraz ${ }^{\text {a,b }}$, E.G. Nascimento ${ }^{\text {c }}$, E.M. Carvalho ${ }^{\text {d }}$, L. Pontes-de-Carvalho ${ }^{\text {a,e }}$ \\ ${ }^{a}$ Centro de Pesquisa Gonçalo Moniz, Fundação Oswaldo Cruz, Salvador, Brazil \\ ${ }^{\mathrm{b}}$ Departamento de Análises Clínicas e Toxicológicas, Faculdade de Farmácia, \\ Universidade Federal da Bahia, Rua Barao de Geremoato S/N Campus de Ordisa, Salvador, Bahia Brazil \\ ${ }^{\mathrm{c}}$ Secretaria de Sáude do Estado da Bahia, $13^{\mathrm{a}}$ DIRES, Jequié, Brazil \\ ${ }^{\mathrm{d}}$ Serviço de Imunologia do Hospital Universitário Prof. Edgar Santos, Universidade Federal da Bahia, Salvador, Brazil \\ ${ }^{\mathrm{e}}$ Escola Bahiana de Medicina e Saúde Pública, Salvador, Brazil
}

Received 21 December 2004; received in revised form 17 February 2006; accepted 17 February 2006

Available online 19 April 2006

\begin{abstract}
Opportunistic infections, due to disease-related immunosuppression, constitute the major cause of death in American visceral leishmaniasis (AVL). Sera from these patients (AVL sera) non-specifically inhibit the in vitro proliferative response of normal human lymphocytes to lectins or antigens. In the present work, the mediation of this inhibition by IgG, immune complexes and low- or very low-density lipoproteins was studied. AVL serum fractions containing proteins with the molecular weight of IgG, and IgG, purified from AVL sera by anion exchange chromatography, did not suppress the lymphoproliferation. Most of the suppressive activity of AVL sera was associated with a fraction containing molecules with molecular weights above $430 \mathrm{kDa}$. This would be compatible with it being due to immune complexes and/or lipoproteins, and not to soluble IL-2 receptors as reported previously. However, neither of the two possibilities seem to be the case, as (1) depletion of immune complexes by protein-A followed by protein-G chromatographies did not affect the serum suppressive activity, (2) no correlation between immune complex contents and suppressive activities in individual sera was observed, and (3) plasma lipoproteins (VLDL and LDL), purified from AVL patients and from healthy individuals, had the same degree of immunosuppressive activity.
\end{abstract}

(C) 2006 Elsevier Ltd. All rights reserved.

Keywords: Leishmania; Lymphocyte; Immunosuppression; IgG; Immune complexes; Lipoproteins

\section{Introduction}

American visceral leishmaniasis (AVL), caused by the protozoan Leishmania infantum [1], is a systemic disease characterized mainly by fever, hepatosplenomegaly, anemia, hiperglobulinaemia and high levels of anti-Leishmania antibodies and autoantibodies [2,3]. AVL patients are usually unable to mount an effective immune response against the parasite and indeed appear to be severely immunosuppressed [4]. This suppression has a strong non-specific component [4], is the major cause of death [5] in AVL cases, and could be mediated by

\footnotetext{
* Corresponding author. Address: Faculdade de Farmácia, Universidade Federal da Bahia, Rua Barão de Geremoabo S/N, Campus de Ondina, 40170290 Salvador, Bahia, Brazil. Fax: +55 712372255.

E-mail address: neci@ufba.br (N.M. Soares).
}

0882-4010/\$ - see front matter (C 2006 Elsevier Ltd. All rights reserved. doi:10.1016/j.micpath.2006.02.005 serum factors, since dilutions as low as $1 \%$ of sera from patients with visceral leishmaniasis (AVL sera) may markedly inhibit the mitogen-driven proliferation of normal peripheral blood mononuclear cells (PBMC) in vitro [3,4]. This inhibition is not specific for the response to a particular mitogen, since PBMC proliferations driven by concanavalin A (Con A), phytohemoagglutinin and pokeweed mitogen are equally inhibited [3]. Moreover, it is not due to a direct binding of a serum or Leishmania component to the mitogen, since the sera does not inhibit the binding of Con A to cell receptors [6]. Different serum components are candidates for mediating this immunosuppression, such as autoantibodies, immune complexes and lipoproteins, in addition to parasite products. For instance, patients with primary intracranial tumors may have a depressed cell-mediated immunity due to IgG antibodies [7]; circulating immune complexes may down-regulate cell-mediated immune responses in patients with schistosomiasis [8]; Leishmania excreted factors may inhibit the response to lectins of normal leukocytes [9] 
and a down-regulatory effect of lipoproteins on lymphocytes have been demonstrated [10]. In addition, soluble IL-2 receptors have been reported as mediating immunosuppressive activity in AVL sera [11]. In the present study, the molecular weights of the suppressive factors from AVL sera, and the possible participation of $\mathrm{IgG}$, immune complexes and low or very low-density lipoproteins in the suppression of the in vitro limphoproliferative responses of normal PBMC to a mitogen were investigated.

\section{Results}

\subsection{Suppressive effect of AVL serum}

Serum samples from AVL patients exerted potent suppressive activity on concanavalin A (Con A)-stimulated normal PBMC cultures, as reported previously (Table 1). The mean counts per minutes from cultures containing a mixture of control healthy donor's and normal AB serum was eight times higher than that from cultures supplemented with a mixture of AVL and normal AB serum.

\subsection{Molecular weights of immunosuppressive factors of AVL sera}

Fractions with high $(>430 \mathrm{kDa})$ molecular weights, obtained by high resolution liquid chromatography from pools of seven AVL sera, suppressed normal donors' PBMC proliferative response to Con A more intensely than fractions with lower molecular weights. The suppressive activity associated with low molecular weight $(<430 \mathrm{kDa}$ fractions $)$ was never above $33 \%$ (Table 2). To test individual sera, fractions with molecular weights above and below $100 \mathrm{kDa}$, obtained by diafiltration and filtration on Amicon membranes, respectively, were tested for suppressive activity. Fractions with molecular weights above $100 \mathrm{kDa}$ from all sera had a suppressive activity on PBMC proliferation in vitro. The low molecular weight fraction of only one of the five AVL patients sera was suppressive (Table 3).

\subsection{Effect of IgG and immune complexes on the lymphoproliferative responses to Con $A$}

To determine whether IgG antibodies contribute to the suppressive activity of AVL patients' sera on lymphoproliferative responses, IgG purified from five AVL sera by anion exchange chromatography was tested on lymphoproliferative assays. No significant differences were observed between results obtained with IgG purified from normal and AVL sera (Fig. 1B). Removal of IgG and immune complexes (Fig. 2A) from AVL sera, by absorption with insolubilized staphylococcal protein $\mathrm{A}$ and protein $\mathrm{G}$, and control absorptions with insolubilized bovine serum albumin, did not decrease their immunosuppressive activity (Fig. 2B). In addition, there was no significant correlation between levels of circulating immune complexes in individual sera and their immunosuppressive activity (Fig. 3).

\subsection{PBMC proliferative response to Con $A$ in the presence of lipoproteins from AVL patients' plasma}

VLDL and LDL, regardless of their being purified from pools of AVL patients' or normal human plasma, inhibited to the same extent the Con A-induced proliferation of health donor's PBMC (Fig. 4). VLDL was more than four times more suppressive than LDL on the in vitro lymphoproliferation.

\section{Discussion}

The present study confirmed that AVL sera suppress the lymphocyte proliferative response to Con A, from 60 to $99 \%$, as previously described in the literature [4]. The intensity of the lymphoproliferation, both in the presence of normal sera and of AVL patients' sera, was highly variable. This is consistent with previously reported data $[3,4]$, and may depend on stochastic variations in the plasma or serum concentrations of suppressive substances, such as lipoproteins and immunoglobulin aggregates. The presence of serum factors that inhibit the immune response in vitro has been demonstrated in several parasitic diseases in addition to leishmaniasis, such as trypanosomiasis,

Table 1

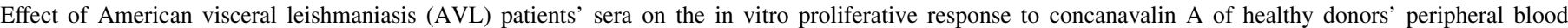
mononuclear cells

\begin{tabular}{|c|c|c|c|c|}
\hline Assay $^{\mathrm{a}}$ & $\begin{array}{l}\text { Normal AB serum } \\
\text { supplemented with }\end{array}$ & Number of tested sera & Lymphocyte response & Percentage of suppression ${ }^{b}$ \\
\hline \multirow[t]{3}{*}{1} & - & 2 & $18,522 \pm 3405^{\mathrm{c}}$ & 0 \\
\hline & Healthy donors' serum & 8 & $29,658 \pm 8810$ & -60 \\
\hline & AVL patients' serum & 10 & $4732 \pm 2267$ & 75 \\
\hline \multirow[t]{3}{*}{2} & - & 2 & $4714 \pm 1474$ & 0 \\
\hline & Healthy donors' serum & 8 & $4282 \pm 1628$ & 10 \\
\hline & AVL patients' serum & 10 & $508 \pm 245$ & 90 \\
\hline \multirow[t]{3}{*}{3} & - & 2 & $3738 \pm 866$ & 0 \\
\hline & Healthy donors' serum & 8 & $3860 \pm 3055$ & -3 \\
\hline & AVL patients' serum & 10 & $1010 \pm 229$ & 73 \\
\hline
\end{tabular}

\footnotetext{
a All cultures were done in the presence of $10 \%$ normal AB human serum, and received no additional serum or were supplemented with $10 \%$ of either healthy donors' or AVL patient's sera.

b The percentages of suppression were calculated as described in Section 4.

c Mean $\pm \mathrm{SD}$ of the mean of the $\left[\mathrm{H}^{3}\right]$ thymidine incorporation of cultures supplemented with the indicated sera, expressed as counts per minute.
} 
Table 2

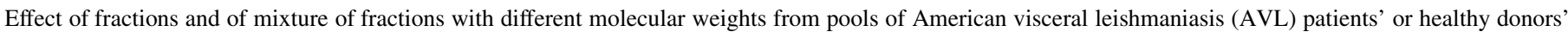
(NHS) sera on the proliferative response of healthy donors' peripheral blood mononuclear cells to concanavalin A

\begin{tabular}{|c|c|c|c|c|}
\hline Experiment $^{\mathrm{a}}$ & Fractions with approximate molecular weights $(\mathrm{kDa})^{\mathrm{b}}$ & Source of fractions & Lymphocyte response & Percentage of suppression ${ }^{\mathrm{c}}$ \\
\hline \multirow[t]{9}{*}{1} & - & - & $12,805 \pm 1086^{\mathrm{d}}$ & 0 \\
\hline & \multirow[t]{2}{*}{$>430$} & AVL & $3713 \pm 1620$ & 71 \\
\hline & & NHS & $7683 \pm 1050$ & 40 \\
\hline & \multirow[t]{2}{*}{$>57<430$} & AVL & $8964 \pm 456$ & 30 \\
\hline & & NHS & $11,396 \pm 3089$ & 11 \\
\hline & \multirow[t]{2}{*}{$>12.4<57$} & AVL & $9092 \pm 542$ & 29 \\
\hline & & NHS & $13,189 \pm 1105$ & -3 \\
\hline & \multirow[t]{2}{*}{$<12.4$} & AVL & $10,756 \pm 3034$ & 16 \\
\hline & & NHS & $12,933 \pm 2905$ & -1 \\
\hline \multirow[t]{7}{*}{2} & - & - & $17,105 \pm 3877$ & 0 \\
\hline & \multirow[t]{2}{*}{$>430$} & AVL & $6276 \pm 1640$ & 63 \\
\hline & & NHS & $13,224 \pm 2984$ & 23 \\
\hline & \multirow[t]{2}{*}{$(>430)+(>12.4<57)$} & AVL & $3573 \pm 644$ & 79 \\
\hline & & NHS & $8946 \pm 416$ & 48 \\
\hline & \multirow[t]{2}{*}{$(>12.4<57)+(<12.4)$} & AVL & $11,403 \pm 1948$ & 33 \\
\hline & & NHS & $16,686 \pm 4905$ & 3 \\
\hline \multirow[t]{7}{*}{3} & - & - & $15,421 \pm 1020$ & 0 \\
\hline & \multirow[t]{2}{*}{$>430$} & AVL & $5493 \pm 1050$ & 64 \\
\hline & & NHS & $12,154 \pm 1054$ & 21 \\
\hline & \multirow[t]{2}{*}{$(>430)+(>12.4<57)$} & AVL & $2831 \pm 524$ & 82 \\
\hline & & NHS & $13,401 \pm 2035$ & 13 \\
\hline & \multirow[t]{2}{*}{$(>12.4<57)+(<12.4)$} & AVL & $10,808 \pm 852$ & 30 \\
\hline & & NHS & $15,534 \pm 704$ & 12 \\
\hline
\end{tabular}

Cultures were supplemented with $6 \mu \mathrm{g} \mathrm{mL}^{-1}$ of concanavalin A, $10 \%$ normal human AB serum and the indicated fractions of healthy donors' or AVL patients' sera.

a Three independent experiments were carried out, each with fractions from different pairs of pools of seven sera (one from healthy donors and one from AVL patients).

b Fractions were obtained by gel-filtration.

c The percentages of suppression were calculated as described in Section 4.

${ }^{d}$ Mean \pm SD of the mean of $\left[\mathrm{H}^{3}\right]$ thymidine incorporation of cultures supplemented with the indicated fractions, expressed as counts per minute.

filariasis and schistosomiasis $[4,8,9,12-16]$, as well as in some non-parasitic illnesses [7,15-17]. The nature of the immunosuppressive serum factors seems to vary in different diseases. In human coccidioidomycosis, they have been shown to be monomeric IgG [15]. Sulica and collaborators [18] have indeed shown that $\mathrm{IgG}$ can have a regulatory effect on $\mathrm{NK}$ cells, reducing their cytolytic activity. The results described herein, however, indicate that the suppressor effect of AVL patients'

Table 3

Suppressive effect of fractions, separated by membrane filtration, on the proliferative response to concanavalin A of AVL patients' or healthy donors' peripheral blood mononuclear cells

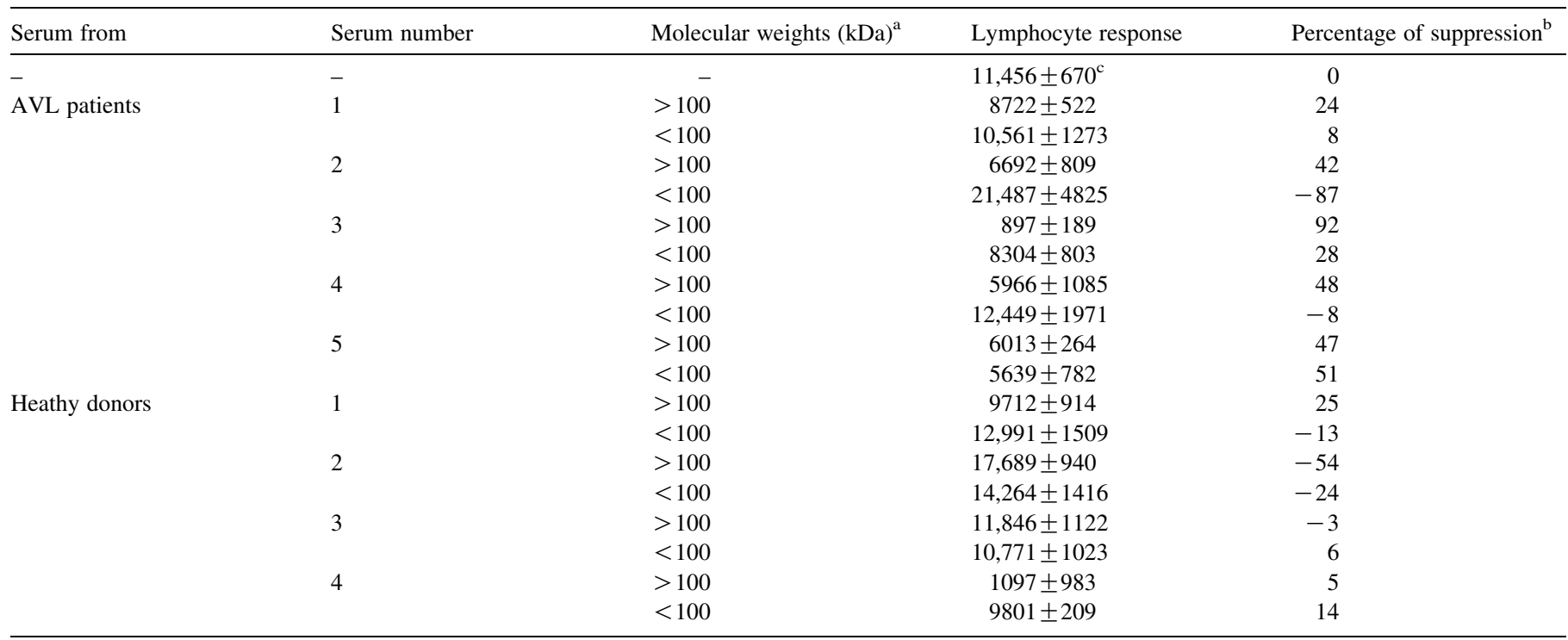

Cultures were supplemented with $6 \mu \mathrm{g} \mathrm{mL} \mathrm{m}^{-1}$ of concanavalin A, $10 \%$ human $\mathrm{AB}$ serum and the indicated fractions of healthy donors' or AVL patients' sera.

${ }^{a}$ Sera were fractionated on an Amersham molecular sieve membrane that excluded molecules with molecular weights above $100 \mathrm{kDa}$, as described in Section 4.

${ }^{\mathrm{b}}$ Calculated as described in Section 4.

${ }^{c}$ Mean \pm SD of the mean of the $\left[\mathrm{H}^{3}\right]$ thymidine incorporation of cultures supplemented with the indicated fractions, expressed as counts per minute. 


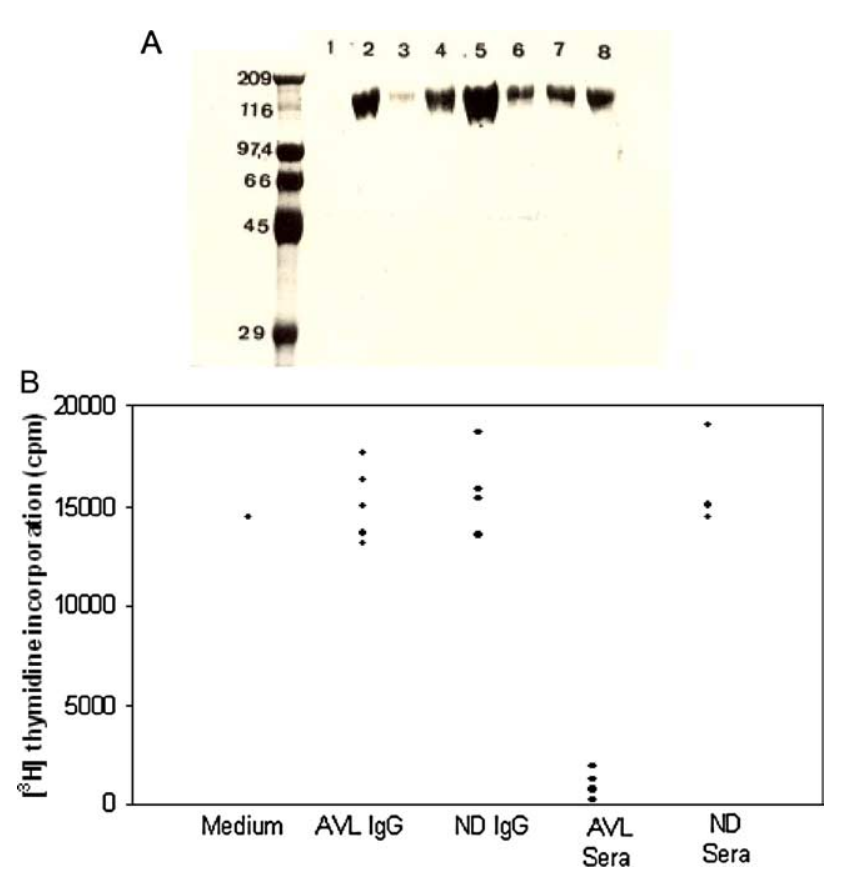

Fig. 1. (A) Polyacrylamide gel electrophoresis in presence of sodium dodecyl sulphate of IgG purified from American visceral leishmaniasis (AVL) patients' (lanes 2, 4,5 and 8) and normal donors' (lanes 1, 3,6 and 7) sera by anion exchange chromatography. The gel was stained with Comassie blue. Molecular weight markers were run in the left lane, and their molecular weights, expressed in $\mathrm{kDa}$, are shown on their left. (B) Peripheral blood mononuclear cell lymphoproliferative response to concanavalin A in the presence of IgG purified from AVL patients' sera (AVL IgG) or from normal donors' human sera (ND IgG). All cultures were carried out in the presence of normal serum from an AB-blood group individual. AVL patients' sera (AVL sera) or normal donors' sera (ND sera) were also tested. Each symbol represents the mean of the results obtained, from testing an individual serum or an individual IgG supplement, in triplicate cultures.

sera on the in vitro lymphoproliferative response is not due to IgG, since purified AVL patients' IgG had no effect on the in vitro lymphoproliferation, and IgG-depletion did not affect the serum suppressive activity. An additional confirmation that monomeric $\mathrm{IgG}$ does not play a role in the immunosuppressive activity of AVL sera came from the absence of this activity in serum fractions, resulting from molecular sieving, containing proteins with the molecular weight of IgG. In fact, as shown herein, most of the suppressive activity of AVL sera was associated with molecules with molecular weights above $430 \mathrm{kDa}$. Barral-Netto and collaborators [11] suggested that soluble IL-2 receptors (sIL-2R), which are present in high concentrations in AVL sera, participate in the AVL serummediated suppression [11,19]. Very little suppressive activity, however, was found in AVL serum fractions with proteins of molecular weights between 12.4 and $57 \mathrm{kDa}$, obtained by gel-filtration, and no suppressive activity in fractions containing proteins of molecular weights below $100 \mathrm{kDa}$, obtained by membrane sieving, in 4 out of 5 sera. Since these fractions would contain the sIL-2R, its participation in the AVL serum immunosuppressive activity is, if any, a minor one.

On the other hand, the association of AVL serum suppressive activity with the larger than $430 \mathrm{kDa}$ fraction would be compatible with it being caused by immune complexes and/or lipoproteins.
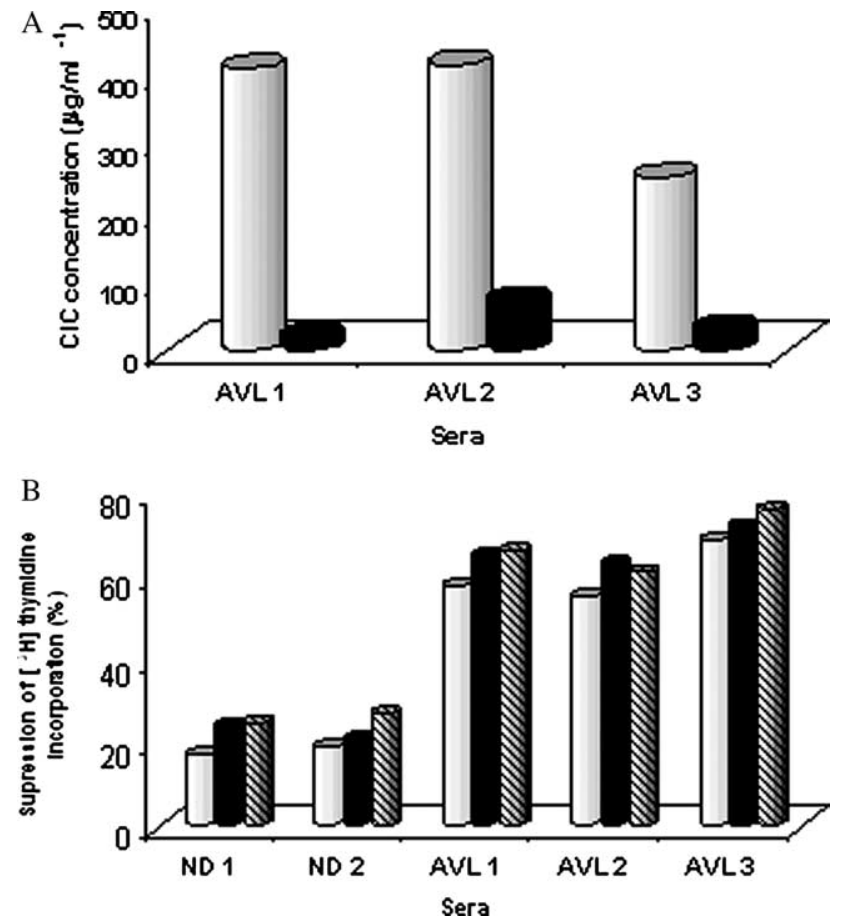

Fig. 2. (A) Circulating immune complex (CIC) concentration in three American visceral leishmaniasis (AVL) patients' sera before ( $\square$ ) and after ( $\square$ ) successive absorptions with protein A and protein $G$ and (B) suppression of normal peripheral blood mononuclear cell proliferative response to concanavalin A in the presence of control and immune complex-depleted sera. The depleted sera were the two normal donor sera (ND 1, ND 2) and the three AVL patients' sera (AVL 1, AVL 2, AVL 3) that produced the data shown in A. $\mathbf{\square}$, unabsorbed sera; $\square$, sera successively absorbed with protein A- and protein GSepharose-4B; sera absorbed with bovine serum albumin-Sepharose-4B.

As shown herein, immune complexes do not seem to participate in the immunosuppressive activity of AVL sera, since their depletion by protein-A followed by protein-G chromatographies did not affect that activity. This was confirmed by the lack of correlation between immune complex concentration and immunosuppressive activities in AVL sera.

Elevated concentrations of lipids are found in AVL sera (N.M. Soares and collaborators, manuscript in preparation). In the sera utilized in this work, however, serum lipid

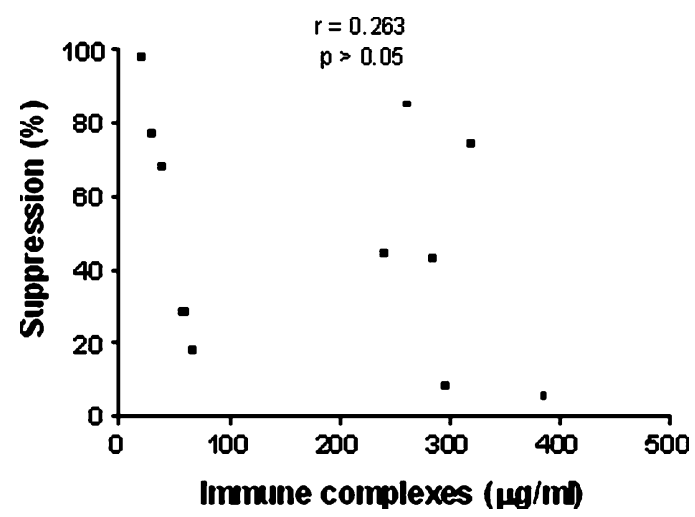

Fig. 3. Lack of correlation between the suppressive activities on the normal peripheral blood mononuclear cell response to concanavalin A and the immune complex contents of American visceral leishmaniasis (AVL) sera. Each symbol represents the data obtained from one individual AVL serum. 


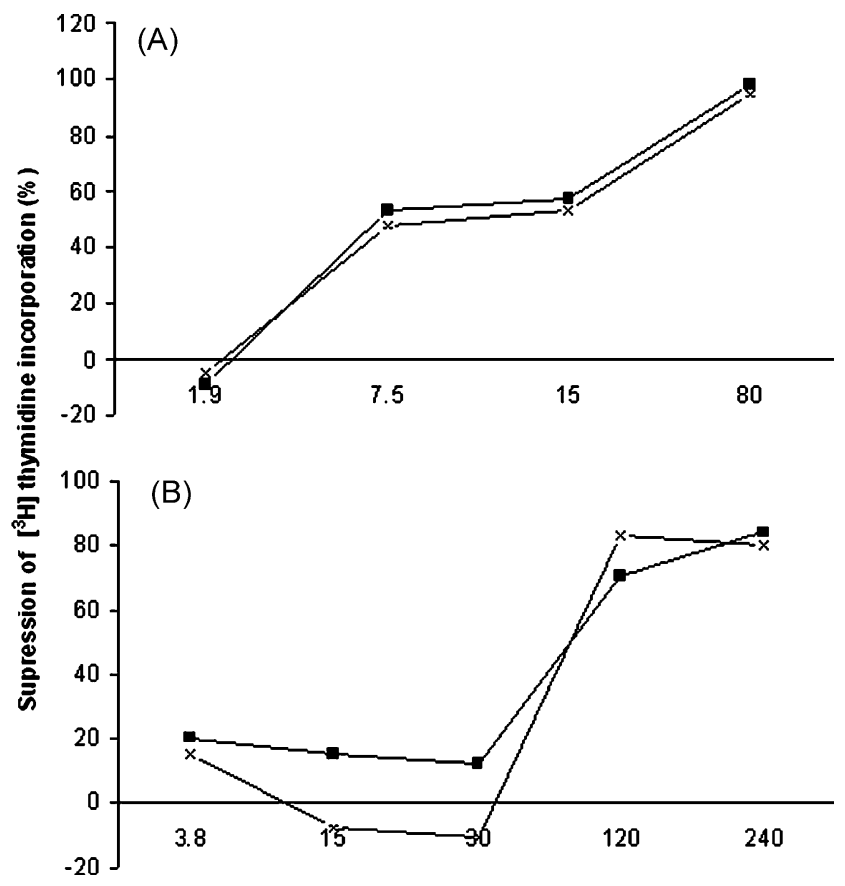

Fig. 4. Effect of lipoproteins from American visceral leishmaniasis (AVL) patients' plasma on the proliferative response to concanavalin A of normal donors' peripheral blood mononuclear cell. The proliferative response was carried out in the presence of VLDL (A) or LDL (B) purified from AVL patients' $(\square)$ or healthy donors' $(X)$ plasmas.

concentrations in AVL patients and healthy donors were similar, possibly because of lipid losses during serum preparation and storage. Physiologic concentrations of lipoproteins in normal human plasma inhibit DNA synthesis by lymphocytes stimulated by alloantigens or mitogens $[10,20-23]$. In the present study, the same degree of immunosuppressive activity of AVL patients' and of healthy individuals' plasma lipoproteins (VLDL and LDL) was shown. In terms of protein concentration, the VLDL had a much more intense inhibitory activity than the LDL, in agreement with previously published results [20,24]. In the physiologic concentration of $30.8 \mu \mathrm{g}$ of protein per milliliter of culture, VLDL caused a suppression of the lymphocyte proliferative response to Con A of around 50\%. HDL has no effect on the mitogen-driven lymphoproliferation of PBMC [10]. Although, as implied from this and from other in vitro studies [10], lipoproteins may always inhibit to a certain extent the immune responses in healthy individuals' (i.e. the lymphoproliferation would be more intense in the absence of lipoproteins), they certainly are not responsible for the AVL serum-mediated suppression studied in the present work and for that described in the literature $[3,4]$, in which sera are collected and stored without special care for preservation of lipoproteins.

As mentioned above, different serum components can exercise immunosuppressive activity, such as hormones [25], alpha-globulin [26], immune complexes [17], monomeric IgG [15], mononuclear cell soluble factors [27] and lipoproteins [10]. In this study, the testing for immunosuppressive activity of AVL serum fractions with different molecular weights allowed the exclusion of some of these components as a major mediator of immunosuppressive activity (e.g. hormones, monomeric $\operatorname{IgG}$ and mononuclear cell soluble factor). Leishmania infection in AVL is systemic, with high parasite burdens. One remaining candidate for mediating the AVL serum suppressive activity would be a high-molecular weight parasite-derived product. This putative high-molecular weight, circulating parasite product should not elicit an antibody response, or it would be present in the form of immune complexes, which, as demonstrated herein, do not seem to mediate the AVL serum suppressive activity. Parasite molecules have indeed been shown to be present in AVL patients plasma and urine [28,29], and Leishmania excreted factors can inhibit in vitro response of immune PBMC to Leishmania and of normal PBMC to phytohemagglutinin and mycobacterial pure protein derivate [9].

Antibodies against Leishmania in vitro excreted factors are not detectable in the sera of patients with leishmaniases (unpublished results), a fact which is compatible with their immunosuppressive activity (they would suppress the antibody response against themselves) and a pre-requirement for their circulation as free, and not part of immune complexes, molecules. A possible approach to investigate the role of parasite molecules as mediators of the AVL serum immunosuppressive activity would be their depletion from the sera with specific antibodies, either polyclonal antibodies against L. chagasi amastigotes or monoclonal antibodies against recombinant antigens with suppressive activity on the in vitro lymphoproliferative response to mitogens.

The present work provides clear-cut information that may be useful in future studies aimed at identifying the circulating suppressive factor in AVL. Further work is also required to ascertain its mechanism of action, which, however, is already known to be independent of cytotoxicity [3]. On the other hand, it is not easy to determine the in vivo relevance of the serummediated immunosupression. The facts that the spleen plays an important role in the defense against blood-borne infections, and that in patients with AVL that organ is pervaded by plasma containing up to 100 times the necessary amount of a factor able to suppress a vigorous mitogen-driven lymphoproliferation in vitro, would strongly argue in favor of an in vivo role for the circulating immunosuppressive factors. These would perhaps inhibit the installation of an effective anti-parasite immune response in the spleen and in the bone-marrow, allowing the typical thriving of Leishmania amastigotes in these organs during AVL.

\section{Materials and methods}

\subsection{Sera}

Sera were from 40 patients with acute AVL (with diagnoses confirmed by direct identification of the parasite), from blood collected before treatment, and from 32 healthy volunteers from areas without L. chagasi transmission. All patients and volunteers were previously informed about and understood the nature of the research, in accordance to institutional ethical guidelines. 


\subsection{Molecular sieving}

AVL patients' or normal sera were fractionated by high resolution liquid chromatography (FPLC) on a Superose 12 column (Pharmacia, Uppsala, Sweden) or by filtration or diafiltration on a Centriprep-100 membrane (100,000 MW cutoff, Amicon, Witten, Germany). The fractions containing different molecular weight molecules were concentrated to the sample original volumes and dialyzed against RPMI 1640 culture medium (GIBCO, Grand Island, NY).

\subsection{IgG purification}

IgG from AVL and normal human serum was purified by anion-exchange FPLC on a HR5/5 Mono Q column (Pharmacia, Uppsala, Switzerland). The fractions containing IgG were pooled and dialyzed against RPMI. The degree of purity was assessed by polyacrylamide gel electrophoresis in presence of dodecyl sulfate (SDS-PAGE) and Comassie blue staining, as described elsewhere [30]. Single bands with molecular weights corresponding to that of $\operatorname{IgG}$ were observed (Fig. 1A).

\subsection{IgG depletion}

Pools $(400 \mu \mathrm{L})$ of five AVL and five normal control sera were passed through a $2 \mathrm{~mL}$ protein A-Sepharose 4B column (Sigma Chemical Company, St Louis, USA), containing $2 \mathrm{mg}$

\subsection{Lymphoproliferative response}

PBMC from healthy volunteers were prepared from heparinized blood by centrifugation over Ficoll-Hypaque (Sigma Chemical Company, St Louis, USA). The cells in the solution interface were washed three times and resuspended in RPMI 1640 culture medium containing antibiotics $\left(100 \mathrm{IU} \mathrm{mL}^{-1}\right.$ of penicillin and $50 \mu \mathrm{g} \mathrm{mL}^{-1}$ of streptomycin), L-glutamine ( $\left.2 \mathrm{mM}\right), N$ 2-hydroxyethypiperasine- $N^{\prime}$-2-ethanesulfonic acid (HEPES, $10 \mathrm{mM}$ ) and $10 \%$ of heat-inactivated human AB serum (Sigma Chemical Company, St Louis, USA; complete medium). $200 \mu \mathrm{L}$ volumes of complete medium containing $2 \times 10^{6}$ PBMC were plated in flat bottomed microtitre plates (Limbro Chemical Co., New Haven, USA). The medium also contained $6 \mu \mathrm{g}$ of concanavalina A (Con A; Sigma Chemical Company, St Louis, USA) per milliliter and the additional supplements: (1) $10 \%$ of either heat-inactivated AVL or normal human sera; (2) IgG purified from AVL or normal human sera; (3) fractions containing molecules with different molecular weights from AVL or normal human sera, (4) IgG- and/or IC-depleted sera from AVL patients or normal individuals or (5) VLDL, LDL or HDL purified from AVL or normal human sera. Negative control cultures were performed in the absence of Con A. The cultures were incubated at $37^{\circ} \mathrm{C}$, in $5 \% \mathrm{CO}_{2}$ atmosphere, for 3 days. DNA synthesis was estimated in a beta-counter after a $12 \mathrm{~h}$ pulse of the cells with $1 \mu \mathrm{Ci}$ of $\left[{ }^{3} \mathrm{H}\right]$ thymidine (New England Nuclear, Boston, MA, USA). Results were extracted from to the mean responses of triplicate cultures, and the degree (\%) of suppression caused by the different supplements was calculated using the formula:

$$
\% \text { suppression }=1-\frac{\text { mean uptake of }\left[{ }^{3} \mathrm{H}\right] \text {-thymidine (mean counts per minute) in wells containing the supplement }}{\text { mean uptake of }\left[{ }^{3} \mathrm{H}\right] \text {-thymidine in wells without the supplement }} \times 100
$$

of protein A per milliliter of gel or through a control bovine serum albumin-Sepharose 4B column.

\subsection{Immune complex (IC) depletion}

Sera $(n=3)$ from AVL and from healthy volunteers $(n=3)$ were depleted of IgG-containing IC by successively absorption on protein A- and protein G-Sepharose 4B columns (Sigma Chemical Company, St Louis, USA). IC concentrations in depleted and in untreated serum were measured as previously described [31]. Sera were also absorbed with bovine serum albumin-Sepharose 4B as a control.

\subsection{Lipoprotein purification}

Lipoprotein-rich fractions were obtained from pooled AVL and normal human serum using ultracentrifugation on a $\mathrm{NaCl}$ gradient, as previously described [32]. VLDL and LDL fractions were dialyzed three times against RPMI 1640 culture medium (GIBCO, Grand Island, NY) and stored at $-20{ }^{\circ} \mathrm{C}$.

\section{References}

[1] Lainson R, Shaw JJ. The leishmaniases. Part 1. Evolution, classification and geographical distribution. London: Academic Press; 1987. p. 27-65.

[2] Carvalho EM, Andrews BS, Martinelli R, Dutra M, Rocha H. Circulating immune complexes and rheumatoid factor in schistosomiasis and visceral leishmaniasis. Am J Trop Med Hyg 1983;32(1):61-8.

[3] Barral A, Carvalho EM, Badaró R, Barral-Netto M. Suppression of lymphocyte proliferative responses by sera from patients with American visceral leishmaniasis. Am J Trop Med Hyg 1986;35:735-42.

[4] Carvalho EM, Bacellar AO. Lymphocyte reactivity to mitogens in American visceral leishmaniasis. Braz J Med Biol Res 1983;16:35-41.

[5] Guerreiro J, Ribeiro S, Carvalho EM, Badaro R, Rocha H. Bacterial infection in patients with visceral leishmaniasis. Mem Inst Oswaldo Cruz 1985;80(4):447-52.

[6] Barral-Neto M, Barral A. A simple method for assessing the binding of concanavalin a to mononuclear cell surfaces: no interference of visceral leishmaniasis serum on this binding. Mem Inst Oswaldo Cruz 1986;81(3): 343-5.

[7] Brooks WH, Netsky GM, Normansell DE, Horwitz DA. Depressed cellmediated immunity in patients with primary intracranial tumors. J Exp Med 1972;136:1631-47.

[8] Cottrell BJ, Huber D, Sturrock RF. An immunosuppressive factor in the serum of patients with schistosomiasis. Trans R Soc Trop Med Hyg 1980; $74: 415-9$. 
[9] Londner MV, Frankenburg S, Slutzky GM, Greenblatt CL. Action of leishmanial excreted factor (EF) on human lymphocyte blast transformation. Parasite Immunol 1983;5:249-56.

[10] Curtiss LK, Edgington TS. Regulatory serum lipoproteins: regulation of lymphocyte stimulation by a species of low density lipoprotein. J Immunol 1976;116:1452-8.

[11] Barral-Netto M, Barral A, Santos SB, Carvalho EM, Badaró R, Rocha H, et al. Soluble IL-2 receptor as an agent of serum-mediated suppression in human visceral leishmaniasis. J Immunol 1991;147:281-4.

[12] Cunninghan D, Kunn RE. Trypanosoma cruzi induced suppressor substances. Part I. Cellular involvement and partial characterization. J Immunol 1980;124:2122-6.

[13] Wyler DJ. Circulating factor from a kala-azar patient suppresses in vitro antileishmanial T cell proliferation. Trans R Soc Trop Med Hyg 1982;76: 304-6.

[14] Lammie PJ, Katz SP, Anderson WHK. Serosuppression in experimental filariasis. Clin Exp Immunol 1984;55:602-10.

[15] Cox RA, Pope RM. Serum-mediated suppression of lymphocyte transformation responses in coccidioidomycosis. Infect Immun 1987;55:1058-62.

[16] Mehra VL, Talwar GP, Galakrisnan K, Bhutani LK. Influence of chemoteraphy and serum factors on the mitogenic response of peripheral leucocytes of leprosy patients to phytohemaglutinin. Clin Exp Immunol 1972;12:205-13.

[17] Dorval G, Yang WH, Goodfriend L, Roy R, Espinoza LR, Hebert J. Circulating immune complexes may be associated with increased suppressor T-cell activity in atopic allergy. Clin Immunol Immunopathol 1980;16:245-53.

[18] Sulica A, Galatiuc C, Manciulea M, Deleo A, Bancu AC, Whiteside TL, et al. Regulation of human natural cytotoxicity by IgG. IV. Association between of monomeric $\operatorname{IgG}$ to the $\mathrm{Fc}$ receptors on large granular lymphocytes and inhibition of natural killer (NK) cell activity. Cell Immunol 1993;147:397-410.

[19] Vital G, Mansueto S, Malta R, Gambino G, Mocciaro C, D’Agostino R, et al. The significance of serum soluble IL-2 receptor as a marker for active visceral leishmaniasis in Sicilian patients. Clin Exp Immunol 1992; 90:219-22.
[20] Chisari FV. Immunoregulatory properties of human plasma in very low density lipoproteins. J Immunol 1977;119:2129-35.

[21] Morse JJ, Witte LD, Goodman DS. Inhibition of lymphocyte proliferation stimulated by lectins and allogenic cells by normal plasma lipoprotein. J Exp Med 1977;146:1791.

[22] Waddell CO, Taunton OD, Twomey JJ. Inhibition of lymphoproliferation by hyperlipoproteinemia plasma. J Clin Invest 1976;58:950-4.

[23] Cuthbert JA, Lipsky PE. Differential regulation of the expression of 3-hydroxy-3-methylglutaryl coenzyme A reductase and low density lipoprotein receptor genes. J Lipid Res 1992;33:1157-63.

[24] Yi PI, Beck G, Zucker S. Membrane receptors for very low density lipoprotein (VLDL) inhibitor of lymphocyte proliferation. Blood 1981; 57:1055-64.

[25] Arya SK, Wong-Stall F, Gallo RC. Dexamethasone mediated inhibition of human $\mathrm{T}$ cell growth factor and gamma interferon messenger RNA. J Immunol 1984;133:273-6.

[26] Cooperbnad SR, Badger AM, Davis RC, Schimd K, Mannick JA. The effect of immunoregulatory \& globulin (IRA)upon lymphocytes in vitro. J Immunol 1972;109:154-63.

[27] Sathish M, Bhutani LK, Sharma AK, Nath I. Monocyte-derived soluble suppressor factor(s) in patients with lepromatous leprosy. Infect Immun 1983;42:890-9.

[28] Attar ZA, Chance ML, El-Safi S, Carney J, Azazy A, El-Hadi M, et al. Latex agglutination test for the detection of urinary antigens in visceral leishmaniasis. Acta Trop 2001;78:11-16.

[29] Azazy AA. Detection of circulating antigens in sera from visceral leishmaniasis patients using dot-ELISA. J Egypt Soc Parasitol 2004; 34(1):35-43.

[30] Laemmli UK. Cleavage of structural proteins during the assembly of the head of bacteriophage T4. Nature 1970;277:680-5.

[31] Soares NM, Santiago MB, Pontes de Carvalho LC. An improved antiC3/IgG ELISA for quantification of soluble immune complexes. J Immunol Methods 2001;249:199-205.

[32] Redgrave TG, Roberts DCK, West CE. Separation of plasma lipoproteins by density-gradient ultracentrifugation. Anal Biochem 1975;65:42-9. 